\title{
Ideias prévias sobre plantas medicinais e tóxicas de estudantes do ensino fundamental da região da Fronteira Oeste do Rio Grande do Sul
}

\author{
Previous ideas about medicinal and poisonous plants of elementary school \\ students of the Rio Grande do Sul West Frontier region
}

\section{Las ideas previas acerca de las plantas medicinales y venenosas de los estudiantes del primaria de la Frontera Occidental del Río Grande do Sul}

${ }^{1}$ Eliziane da Silva Dávila; ${ }^{2}$ Cristiane da Cunha Alves; ${ }^{3}$ Bianca Maria de Lima; ${ }^{4}$ Vanderlei Folmer; ${ }^{5}$ Robson Luiz Puntel

1 elizianedavila@unipampa.edu.br, Universidade Federal do Pampa; ${ }^{2}$

crisalves1917@hotmail.com, Universidade Federal do Pampa; ${ }^{3}$ biancalima17@live.com, Universidade Federal do Pampa; ${ }^{4}$ VanderleiFolmer@unipampa.edu.br, Universidade Federal do Pampa; ${ }^{5}$ RobsonPuntel@ unipampa.edu.br, Universidade Federal do Pampa.

\begin{abstract}
Resumo
Faz parte da cultura popular brasileira a utilização de plantas com fins medicinais. Entretanto, se não forem utilizadas corretamente, podem ter efeito contrário. Também existe outro grupo de plantas que os brasileiros gostam de ter em casa, as ornamentais, que muitas delas produzem princípios ativos tóxicos. Dentro deste contexto, este estudo teve por finalidade investigar as concepções prévias dos estudantes de ensino fundamental de duas escolas públicas do município de Uruguaiana - RS acerca das plantas medicinais e tóxicas. Aplicaram-se algumas questões abertas aos estudantes e as respostas foram categorizadas por meio da análise de conteúdo. Os resultados demonstraram que os estudantes possuem um conhecimento antropocêntrico em relação às plantas, sendo o grupo das plantas medicinais que podem fazer bem ao ser humano e as plantas tóxicas com efeito contrário. Nenhum estudante relatou o efeito nocivo que as plantas consideradas medicinais podem ocasionar dependendo da dosagem administrada. Poucos estudantes relataram terem estudado sobre este grupo de vegetais na escola. Conclui-se que é relevante abordar este tema em sala de aula, pelo seu caráter e relevância social, bem como para contextualizar os saberes escolares com assuntos relacionados à realidade dos estudantes auxiliandoos na reconstrução dos seus conhecimentos.
\end{abstract}

Palavras-Chave: saberes populares, concepções prévias, ensino de ciências, plantas medicinais, plantas tóxicas.

\begin{abstract}
It is part of Brazilian popular culture the use of plants for medicinal purposes. However, if not used properly, can have the opposite effect. There is also another group of plants that the Brazilians like to take home, ornamental, many of them produce toxic active ingredients. Within this context, this study aimed to investigate the preconceptions of elementary students from two public schools in the city of Uruguaiana - RS about the medicinal and poisonous plants. They applied to some issues open to students and the answers were categorized by content analysis. The results showed that the students have an anthropocentric knowledge in relation to plants, and the group of medicinal plants that may do well to human and toxic plants with opposite effect. No student reported the adverse effect that may cause medicinal plants considered depending on the dosage administered. Few students reported having studied this group of vegetables at school. It concludes that it is relevant to this topic in the classroom, by his character and social relevance, and to contextualize the school knowledge with reality matters related to students helping them in the reconstruction of their knowledge.
\end{abstract}

Keywords: popular knowledge, preconceptions, science education, medicinal plants, poisonous plants.

\section{Resumen}

Es parte de la cultura popular brasileña el uso de plantas con fines medicinales. Sin embargo, si no se utiliza correctamente, puede tener el efecto contrario. También hay otro grupo de plantas que los brasileños les gusta 
llevar a casa, ornamental, muchos de ellos producen ingredientes activos tóxicos. Dentro de este contexto, el presente estudio tuvo como objetivo investigar las preconcepciones de los estudiantes de primaria de dos escuelas públicas en la ciudad de Uruguaiana - RS sobre las plantas medicinales y venenosas. Ellos aplican a algunas cuestiones abiertas a los estudiantes y las respuestas se clasificaron mediante el análisis de contenido. Los resultados mostraron que los estudiantes tienen un conocimiento antropocéntrica en relación a las plantas, y el grupo de plantas medicinales que pueden hacer bien a las plantas humanos y tóxicas con efecto contrario. Ningún estudiante informó el efecto adverso que pueden causar las plantas medicinales consideradas en función de la dosis administrada. Pocos estudiantes reportaron haber estudiado este grupo de hortalizas en la escuela. Se concluye que es relevante a este tema en el aula, por su carácter y relevancia social, y para contextualizar el conocimiento escolar con asuntos realidad relacionados con los estudiantes ayudándoles en la reconstrucción de sus conocimientos.

Palabras clave: conocimiento popular, preconcepciones, educación científica, plantas medicinales, plantas venenosas.

\section{Introdução}

A relação do homem com as propriedades das plantas é datada desde a antiguidade, que sempre as utilizou de formas variadas, como por exemplo, para alimento, aquecimento, construção de abrigos e moradias, vestuário, e, em especial para fins medicinais, que por alguns povos, a cura era relacionada ao poder mágico e sobrenatural das plantas (KOVALSKI, OBARA e FIGUEIREDO, 2011).

Atualmente as plantas consideradas vegetais ainda são muito utilizadas, apesar da crescente produção de medicamentos pela indústria farmacêutica. Segundo os dados da Organização Mundial da Saúde - OMS (2000), 80\% da população dos países em desenvolvimento, faz uso de práticas tradicionais na atenção primária, e desse total, $85 \%$ usa plantas medicinais ou preparações destas.

No Brasil, aproximadamente $82 \%$ da população faz uso de plantas medicinais para cuidar de algum aspecto da saúde, seja através da medicina tradicional indígena, quilombola, entre outros povos e comunidades tradicionais, seja pelo uso da medicina popular (RODRIGUES; DE SIMONI, 2010). Este último tipo de medicina é composto por saberes populares, que segundo Xavier e Flôr (2015) são como "um conjunto de conhecimentos elaborados por pequenos grupos (famílias, comunidades), fundamentados em experiências ou em crenças e superstições, e transmitidos de um indivíduo para outro, principalmente por meio da linguagem oral e dos gestos". Gondim e Mól (2008) mencionam que chás medicinais, artesanato, mandingas, cantigas de ninar, culinária podem ser considerados exemplos deste tipo de conhecimento e complementam que os mesmos são passivos de modificações por serem integrantes de certa cultura.

Entretanto, a transmissão do conhecimento popular através de geração a geração e o fácil acesso às plantas medicinais pode levar muitas pessoas a usarem indiscriminadamente 
estes vegetais sem terem conhecimento dos riscos, devido à quantidade utilizada do principio ativo, ocasionando uma intoxicação (NICOLETTI et al, 2007; KOVALSKI e OBARA, 2013).

Além das plantas com potencial medicinal, há outro grupo de vegetais que merecem atenção, as plantas consideradas tóxicas, que segundo Albuquerque (1980)

“as plantas tóxicas são aquelas que possuem substâncias que, por suas propriedades naturais, físicas, químicas ou físico-químicas, alteram o conjunto funcional-orgânico em vista de sua incompatibilidade vital, conduzindo o organismo vivo a reações biológicas diversas. O grau de toxidade depende da dosagem e do indivíduo, embora haja substâncias tóxicas que, em dosagens mínimas, entram na composição de vários remédios."

Segundo o Sistema Nacional de Informações Toxico Farmacológicas (SINITOX) no ano de 2012 houve 1185 casos registrados de intoxicação por plantas, sendo que 960 casos ocorreram nas zonas urbanas. As regiões brasileiras que mais tiveram registro foram o Sudeste, Sul e Centro-Oeste respectivamente.

Não somente as plantas tóxicas podem causar problemas de saúde, como também as plantas medicinais, se não forem utilizadas corretamente. Dentro deste contexto, as escolas poderiam auxiliar a comunidade com a abordagem destas plantas em sala de aula para auxiliar no maior conhecimento destes vegetais e evitar casos de intoxicação.

Paiva, Almeida e Martins (2015) mencionam que a escola é o local onde deve acontecer a articulação dos conhecimentos de diversas áreas com o contexto sociocultural em que o aluno está inserido através de um ensino que procure dialogar com outras interpretações de mundo, de culturas para formar um estudante crítico da sua realidade.

Deste modo, se os professores recorrerem a uma didática que estabeleça uma mediação entre o conhecimento popular com o conhecimento científico abordado na formação escolar pode-se reduzir a distância entre estes saberes, favorecendo o processo de ensinoaprendizagem, pois possibilita o envolvimento do aluno no processo de construção do seu conhecimento (COSTA, 2008).

Uma estratégia que pode ser utilizada para obter o saber popular dos estudantes é através do levantamento das concepções prévias dos estudantes. Silva e Núñez (2007) mencionam que as ideias prévias são o que o sujeito constrói para interpretar e explicar eventos naturais cotidianos; são construções que os estudantes elaboram para dar resposta às 
necessidades pessoais de interpretar fenômenos naturais. Tais ideias resultam da interação com o outro nos cenários socioculturais. Por meio das concepções prévias, o professor pode organizar suas aulas atendendo à realidade e necessidades dos estudantes e do meio em que está inserido (BAPTISTA, 2010).

Em função do cenário exposto acima, este trabalho teve como objetivo averiguar as concepções prévias dos estudantes do ensino fundamental acerca das plantas medicinais e tóxicas para poder orientar práticas pedagógicas alternativas no ambiente escolar com a utilização dos conhecimentos populares.

\section{Metodologia}

O presente trabalho faz parte de um estudo maior de doutorado intitulado "Uso de plantas tóxicas e medicinais como tema contextualizador no ensino de ciências e na formação continuada de professores da educação básica" que tem como intuito avaliar um tema do saber popular como uma proposta pedagógica alternativa para o ensino de ciências que auxilie na formação de cidadãos críticos e reflexivos da sua realidade.

Este trabalho é de caráter quali-quantitativo, descritivo e exploratório, tendo como público-alvo 44 estudantes de $7^{\circ}$ ano do ensino fundamental de 2 escolas públicas do município de Uruguaiana - RS. A escolha das escolas ocorreu devido à localização geográfica, sendo uma delas localizada no centro da cidade e a outra situada na periferia do município. Foram realizados os seguintes questionamentos: "Na sua opinião, o que é uma planta medicinal?”; "Quais as plantas medicinais que você conhece?”; "Na sua opinião, o que é uma planta tóxica?”; "Quais as plantas tóxicas que você conhece?”; "Você já estudou plantas medicinais elou tóxicas na escola? Se a resposta for SIM, diga-nos em qual disciplina e como aconteceu a atividade."

As respostas foram analisadas através da análise de conteúdo de Bardin (2004).

\section{Resultados e Discussão}

Os resultados demonstraram que a maior parte dos estudantes investigados consideram como uma planta medicinal aquela que pode fazer bem ao ser humano, servindo como remédio para curar enfermidades e/ou sintomas, como visto nas falas dos seguintes estudantes:

\section{E 7: “É uma planta que serve de remédio".}




\section{E 13: "Uma planta que cura doenças".}

E 18: "As plantas medicinais ajudam a curar dor de barriga".

Resultados semelhantes foram encontrados por Cruz, Furlan e Joaquim (2009) com alunos dos sétimos e oitavos anos do ensino fundamental de cinco escolas da rede particular do município São José dos Campos - SP e por Silva e Marisco (2013) com estudantes da Educação de Jovens e Adultos de Vitória da Conquista - Bahia onde 49,2\% dos alunos associou o conceito de plantas medicinais com o tratamento e cura de enfermidades, se aproximando parcialmente do conceito proposto pela OMS.

Também foi verificado uma concepção de que plantas medicinais são aquelas que fazem bem ao ser humano, como observado na fala do estudante 11 "O que faz bem para a saúde.”. É preciso ter cuidado com este tipo de concepção, pois o estudante pode não estar identificando nenhum perigo nestes vegetais devido o mesmo pertencer a natureza. Segundo Nicoletti et al (2007) a falsa concepção de que "medicamento natural, se não fizer bem, mal não faz" contribui para que ocorram casos de intoxicações. Em função dos estudantes não perceberem os malefícios que estes vegetais podem ocasionar pelo uso incorreto, pode acabar acarretando em sérias consequências sendo necessária uma implementação de medidas de educação e informação que colabore para seu uso racional (OLIVEIRA e GONÇALVES, 2006). Somente um estudante (E2) mencionou que as plantas medicinais também podem trazer malefícios ao ser humano, e que nem sempre a doença é curada com estes vegetais.

Outra concepção analisada foi em função da produção de alguns medicamentos com princípios ativos vegetais e que estes devem ser manipulados por profissionais capacitados:

E 4: "É uma planta que serve para extração elou fabricação de remédios, feito por médicos capacitados, cientistas e especialistas."

Silva e Marisco (2013) também encontraram em menor porcentagem este tipo de conhecimento, apenas $11,4 \%$ dos alunos apresentaram o entendimento de que as plantas medicinais estão relacionadas com a produção de remédios ou que possuem substâncias que são ponto de partida para os remédios sintéticos.

No que concerne ao conhecimento de exemplares de plantas medicinais, verificou-se que os estudantes citaram vários vegetais com potencial medicinal, dentre eles, estão o Boldo $(36,6 \%)$, Macela $(36,6 \% \%)$, Camomila $(13,6 \%)$ e a Erva Cidreira (11,3\%) (Tabela 01), mesmas plantas apontadas no estudo de etnobotânica do município de Uruguaiana de Galvani e Barreneche (1994) onde observaram que é muito comum o uso da fitoterapia como forma de prevenção e cura das mais diversas sintomatologias vinculadas às doenças. Os vegetais Boldo 
e Camomila também foram os mais mencionados nos estudos de Cruz, Furlan e Joaquim (2009).

Tabela 01 - Plantas medicinais mais citadas pelos estudantes do $7^{\circ}$ ano do ensino fundamental do município de Uruguaiana - RS

\begin{tabular}{lc}
\hline \multicolumn{1}{c}{ Plantas medicinais } & TOTAL \\
\hline Boldo & $16(36,3 \%)$ \\
Macela & $16(36,3 \%)$ \\
Não sei / Nenhum (a) / Não respondeu & $15(34 \%)$ \\
Camomila & $6(13,6 \%)$ \\
Erva cidreira & $5(11,3 \%)$ \\
Hortelã & $5(11,3 \%)$ \\
Laranjeira & $4(9 \%)$ \\
Pitangueira & $4(9 \%)$ \\
Limoeiro & $3(6,8 \%)$ \\
Erva doce & $2(4,5 \%)$ \\
Malva & $2(4,5 \%)$ \\
Penicilina & $2(4,5 \%)$ \\
Amoeira & $1(2,3 \%)$ \\
Alecrim & $1(2,3 \%)$ \\
Arruda & $1(2,3 \%)$ \\
Melissa & $1(2,3 \%)$ \\
Sene & $1(2,3 \%)$ \\
Raiz de Santa Maria & $1(2,3 \%)$ \\
\hline
\end{tabular}

Em relação ao conhecimento das plantas tóxicas, a maioria dos estudantes mencionou que são vegetais que podem fazer mal a saúde do ser humano, causando desde reações alérgicas até complicações mais sérias, como a morte do indivíduo. Sete estudantes (16\%) caracterizaram estas plantas por conterem veneno e/ou toxinas prejudiciais à saúde e a maioria deles complementou que esta substância era liberada para o ambiente ou para o ser humano quando entrasse em contato com a espécie, como pode ser visto nas falas abaixo:

E 4: "É uma planta que tem algum veneno ou toxina transferida pelo ar nos seres vivos".

E 11: "A planta tóxica é a planta que pode soltar um gás tóxico pela boca”.

E 12: “Larga veneno”.

E 18: "É uma planta que solta uma toxina”.

E 27: "É uma planta que tem toxina e se você toca em uma planta tóxica e não lava a mão você fica doente”. 
Houve também um aluno que caracterizou as plantas tóxicas através de uma função vital a todos os vegetais, como observado na fala do estudante E 24 "planta tóxica é uma planta que precisa de ar para sobreviver", enfatizando, mais uma vez, o desconhecimento destas plantas.

Somente três estudantes mencionaram que as plantas tóxicas podem prejudicar o ambiente e outros seres vivos além do ser humano.

\section{E 23: "É uma planta que prejudica o meio ambiente".}

E 9: "Aquela que faz mal a saúde humana e dos animais".

Também houve estudantes que não responderam a esta questão.

Quanto aos exemplares de plantas tóxicas conhecidas pelos estudantes, observou-se que ocorreu em menor número do que as plantas medicinais, entre as mais citadas estão Urtiga e Espada de São Jorge (Tabela 02). Chama a atenção que a maioria dos estudantes não respondeu a esta questão, sendo o reflexo do desconhecimento deste grupo de vegetais que está presente no seu cotidiano e um alerta de um tema que deve ser abordado mais nas escolas.

Tabela 02 - Plantas tóxicas mais citadas pelos estudantes do $7^{\circ}$ ano do ensino fundamental do município de Uruguaiana - RS

\begin{tabular}{|c|c|}
\hline Plantas tóxicas & TOTAL \\
\hline Não sei / Nenhum (a) / Não respondeu & $26(59 \%)$ \\
\hline Urtiga & $4(9 \%)$ \\
\hline Espada de São Jorge & $3(6,8 \%)$ \\
\hline Boldo & $2(4,5 \%)$ \\
\hline Comigo-Ninguém-Pode & $2(4,5 \%)$ \\
\hline Copo de Leite & $2(4,5 \%)$ \\
\hline Babosa & $1(2,3 \%)$ \\
\hline Coroa de Cristo & $1(2,3 \%)$ \\
\hline Hortelã & $1(2,3 \%)$ \\
\hline Macela & $1(2,3 \%)$ \\
\hline Mamona & $1(2,3 \%)$ \\
\hline Não-me-toque & $1(2,3 \%)$ \\
\hline Paraíso & $1(2,3 \%)$ \\
\hline Penicilina & $1(2,3 \%)$ \\
\hline Planta carnívora & $1(2,3 \%)$ \\
\hline
\end{tabular}

Com relação à tabela, cabe ressaltar mais dois aspectos. Primeiramente observam-se vários exemplares de plantas com potencial medicinal sendo citadas pelos estudantes como plantas tóxicas (Boldo, Babosa, Hortelã, Macela e Penicilina) apesar de não terem apresentado em suas concepções de planta medicinal que este grupo poderia causar algum malefício. Isto pode estar relacionado à experiências vividas com estas plantas, onde não 
houve cura e/ou melhora de uma enfermidade e/ou sintoma e pode ter tido um episódio desagradável, seja por uma reação adversa do organismo, interação com medicamentos, identificação errônea da espécie medicinal e/ou uso incorreto (seja na dosagem e/ou preparo) destes vegetais.

O segundo aspecto a ser destacado é em relação à percepção de planta carnívora como uma planta tóxica. Este fato pode estar atrelado aos estereótipos que são feitos desta espécie na mídia, apresentando-a como uma espécie agressiva, perigosa. Bizzeril et al (2007) ao analisar as concepções de estudantes da $7^{\mathrm{a}}$ série de duas escolas públicas do Distrito Federal verificaram como um fator comum nas ilustrações, a agressividade relacionada à estas plantas, onde apresentavam sobrancelhas franzidas, dentes afiados, além de sorrisos sarcásticos e textos como: "planta macabra", “cuidado!", “morte” e "não toque!”, além de observar que $11 \%$ dos alunos desenharam pessoas fugindo de plantas carnívoras, ou então, sendo devoradas por estas. Neste mesmo estudo foi questionado aos alunos a respeito das fontes de informação relacionadas ao seu conhecimento de plantas carnívoras e constataram como principais fontes os desenhos animados, vídeos-games e filmes. Os pesquisadores argumentam que de fato, as plantas carnívoras presentes na mídia foram o principal meio inspiração para muitos dos adolescentes. Alguns esboços constituíram-se em cópias dos estereótipos de plantas representadas nos veículos de comunicação.

Quando questionados se estudaram plantas medicinais e tóxicas na escola, notou-se em relação à planta tóxica que nenhum estudante havia estudado este grupo no ambiente escolar e quanto à plantas medicinais, poucos deles tiveram acesso na sala de aula aos conhecimentos referentes à estes vegetais, porém, este foi realizado através de livros didáticos e exercícios do mesmo e trabalhos de pesquisa, nenhum teve uma abordagem de contextualização e problematização do assunto.

Conforme Kovalski, Obara e Figueiredo (2011), a escola necessita abordar mais os conhecimentos do cotidiano, os tradicionais e populares que fazem parte da vida e da cultura dos educandos, entretanto, o que ocorre na maioria das vezes, é que o ambiente escolar acaba por não contemplá-lo.

\section{Considerações Finais}

Em função dos dados apresentados anteriormente, percebe-se a importância de investigar as concepções prévias dos estudantes, principalmente pelo docente em sala de aula, pois este tipo de análise poderá orientar para a prática pedagógica mais adequada a ser 
utilizada com seus estudantes, tendo maiores chances de promover uma aprendizagem significativa.

Verificou-se que há riscos de ocorrer casos de intoxicação entre os estudantes por alguns terem a concepção de que "tudo que é natural, não faz mal", pois através deste pensamento, o estudante não terá o devido cuidado com a identificação correta, quantidade, preparo e parte da planta que será administrado, bem como, aqueles vegetais, que naturalmente produzem substâncias tóxicas e que por seu desconhecimento, podem ocasionar acidentes.

Também pode-se constatar através das concepções destes grupos vegetais alguns problemas relacionados aos conteúdos escolares, como visto sobre as plantas carnívoras, atribuindo estereótipos que estão vinculados aos meios de comunicação e entretenimento que não correspondem ao vegetal, assim como algumas partes anatômicas que são pertencentes ao grupo dos animais, evidenciando como um estudo das concepções dos estudantes possui sua relevância, pois através dele, pode-se detectar confusões, ideias errôneas, deficiências, dificuldades de aprendizagem que se trabalhado de outra forma em sala de aula, talvez não pudesse ser detectado num primeiro momento e assim o professor já pode deste o início realizar seu planejamento tendo como base um parâmetro inicial de seus estudantes.

Estes resultados evidenciam a importância de serem abordados na sala de aula temas provenientes do saber popular, pois assim, o docente estará promovendo um ensino multicultural, onde o estudante poderá confrontar os diferentes saberes populares com os científicos, podendo refletir e reconstruir seu conhecimento, e desta forma, estar mais ciente dos riscos e benefícios das plantas medicinais e tóxicas, levando-o a ter mais cuidado e tomar decisões mais racionais com este grupo de vegetais. Além disso, ao incluir um tema como esse, o docente estará promovendo a contextualização do conhecimento científico da sua área com um tema do cotidiano do estudante, levando-o a perceber a importância dos conhecimentos escolares na sua vida, além de estar auxiliando na formação de um cidadão crítico e reflexivo da sua realidade, que utilizará as plantas medicinais de forma mais consciente e racional, além de auxiliar a evitar acidentes com o uso incorreto ou indiscriminado destas plantas ou acidentes com as plantas de potencial tóxico.

\section{Referências bibliográficas}

ALBUQUERQUE, J. M. Plantas tóxicas no Jardim e no Campo. FCAP. Belém. 1980. 120 p. 
BAPTISTA, G. C. S. Importância da demarcação de saberes no ensino de ciências para sociedades tradicionais. Ciência \& Educação, v. 16, n. 3, p. 679-694, 2010.

BARDIN, L. Análise de Conteúdo. Lisboa: Edições 70. 2004.

BIZERRIL, M. X. A.; LOUZADA-SILVA, D.; ROCHA, D. M. S.; PERES, J. M.; FURONI, G. L.; Percepção de alunos de ensino fundamental sobre a biodiversidade: relações entre nomes de organismos, mídia e periculosidade. In: VI Encontro Nacional de Pesquisa em Educação em Ciências, Florianópolis, 2007. Disponível em: <www.fae.ufmg.br/abrapec/viempec/CR2/p319.pdf>. Acesso em: 25 de maio de 2015.

COSTA, R. G. A. Os saberes populares da etnociência no ensino das ciências naturais: uma proposta didática para aprendizagem significativa. Revista Didática Sistêmica, v. 8. 2008.

CRUZ, L. P.; FURLAN, M. R.; JOAQUIM, W. M. O estudo de plantas medicinais no ensino fundamental: uma possibilidade para o ensino da botânica. VII Encontro Nacional de Pesquisa em Educação em Ciências - ENPEC. Florianopolis: SC - ABRAPEC. Nov. 2009.

FUNDAÇÃO OSWALDO CRUZ/ SISTEMA NACIONAL DE INFORMAÇÕES TÓXICOFARMACOLÓGICAS (FIOCRUZ/SINITOX). Casos, Óbitos e Letalidade de Intoxicação Humana por Agente e por Região. Brasil, 2012. Disponível em: http://www.fiocruz.br/sinitox/media/Tabela\%203_2012.pdf. Acesso em 28 nov. 2015.

FUNDAÇÃO OSWALDO CRUZ/ SISTEMA NACIONAL DE INFORMAÇÕES TÓXICOFARMACOLÓGICAS (FIOCRUZ/SINITOX). Casos Registrados de Intoxicação Humana por Agente Tóxico e Zona de Ocorrência. Brasil, 2012. Disponível em:

http://www.fiocruz.br/sinitox/media/Tabela\%203_2012.pdf. Acesso em 28 nov. 2015.

GALVANI, F. R.; BARRENECHE, M. L. Levantamento das espécies vegetais utilizadas em medicina popular no município de Uuruguaiana (RS). Revista da FZVA, v. 1, n.1, p. 1 - 14, 1994.

GONDIM, M. S. C.; MÓL, G. S. Saberes populares e ensino de ciências: possibilidades para um trabalho interdisciplinar. Química Nova na Escola, no 30, p. 3 - 9, nov. 2008.

KOVALSKI, M. L.; OBARA, A. T.; FIGUEIREDO, M. C. Diálogo dos saberes: o conhecimento científico e popular das plantas medicinais na escola. VIII Encontro Nacional de Pesquisa em Educação em Ciências - ENPEC. Campinas: SP - ABRAPEC. Dez. 2011.

KOVALSKI, M. L.; OBARA, A. T. O estudo da etnobotânica das plantas medicinais na escola. Ciência \& Educação, Bauru, v. 19, n. 4, p. 911 - 927, 2013.

NICOLETTI, M. A.; OLIVEIRA - JUNIOR, M. A.; BERTASSO, C. C.; CAPOROSSI, P. Y.; TAVARES, A. P. L. Principais interações no uso de medicamentos fitoterápicos. Informa, v. 19, nº1/2, p. $32-40.2007$.

OLIVEIRA, F. Q.; GONÇALVES, L. A. Conhecimento sobre plantas medicinais e fitoterápicos e potencial de toxidade por usuários de Belo Horizonte, Minas Gerais. Revista Eletrônica de Farmácia, v.3, n.2, p. 36-41. 2006. 
ORGANIZAÇÃO MUNDIAL DA SAÚDE (OMS). Situación regulamentaria de los medicamentos: uma resena mundial. Organização Panamericana da Saúde. Washington: OPAS, 2000. 62p.

PAIVA, A. S.; ALMEIDA, R. O.; MARTINS, K. V. Ciência e outras culturas: proposições para o ensino de ciências e biologia. $4^{\circ}$ Congresso Ibero-Americano em Investigação Qualitativa - $4^{\circ}$ CIAIQ / $6^{\circ}$ Simpósio Internacional de Educação e Comunicação - $6^{\circ}$ SIMEDUC, Aracaju: SE, p. 390 - 393. Ago. 2015.

RODRIGUES, A. G.; DE SIMONI, C. Plantas medicinais no contexto de políticas públicas. Informe Agropecuário, Belo Horizonte, v. 31, n. 255, p. 7-12, mar./abr. 2010.

SILVA, M. G. L.; NÚÑEZ, I. B. Concepções alternativas dos estudantes. Programa Universidade a Distância - UNIDIS Grad. 2007. 15 p.

XAVIER, P. M. A.; FLÔR, C. C. C. Saberes populares e educação científica: um olhar a partir da literatura na área de ensino de ciências. Revista Ensaio, Belo Horizonte, v.17, n. 2, p. 308-328. Maio-ago. 2015. 